\title{
Batı Karadeniz Havzası yağış değişkenliklerinin entropi tabanlı bir yaklaşımla değerlendirilmesi
}

\author{
Evaluation of precipitation variability in the Western Black Sea Basin with an entropy- \\ based approach
}

Filiz BARBAROS*1,a

${ }^{1}$ Dokuz Eylül Üniversitesi, Mühendislik Fakültesi, İnşaat Mühendisliği Bölümü, Tinaztepe Kampüsü, 35390 Buca, İzmir

• Geliş tarihi / Received: 14.09.2021 • • Düzeltilerek geliş tarihi / Received in revised form: 19.12.2021 • Kabul tarihi / Accepted: 01.01.2022

\section{$\ddot{O} z$}

Küresel iklim değişikliğinin meteorolojik koşullar üzerindeki en belirgin etkisi sıcaklık ve yağışlar üzerinedir. Son yıllarda görülme sıklıkları artan gerek taşkın gerekse kuraklık olaylarının canlı hayat üzerindeki olumsuz etkileri, gün geçtikçe belirgin bir şekilde karşımıza çıkmaktadır. Yaşanan tüm doğal afetler iklim değişikliğinin önemini daha çok ortaya koyarken, meteorolojik olayların değerlendirilmesini de daha önemli bir noktaya taşımaktadır. Bu amaçla, Batı Karadeniz Havzasındaki yağış gözlem verileri incelenerek, yağış değişkenliği ve bu değişkenliğe bağlı olası risk bölgeleri tanımlanmış, bölgesel analiz sonucu risk haritaları elde edilmiştir. Bu amaçla, Batı Karadeniz Havzasında bulunan 13 adet meteoroloji istasyonuna ait uzun dönem yağış verileri ele alınarak, gözlenen yağışlardaki değişkenlik Şiddet Entropisine (ŞE) dayalı Şiddet Değişkenliği İndisi (ŞDİ) ile tanımlanmıştır. Yağışlardaki değişkenlikler indisler ile tanımlandıktan sonra, bu indislere bağlı oluşturulan indis temelli haritalar ile olasılığa bağlı yüksek yağış alabilecek bölgeler belirlenmiştir. Elde edilen entropi tabanlı haritalar, iklim değişikliği ve taşkın riski ile mücadelede karar vericilerin oluşturacakları planlamalar çerçevesinde etkili bir araç olacaktır.

Anahtar kelimeler: Batı Karadeniz Havzası, Değişkenlik, Entropi, Şiddet değişkenlik indisi, Yağış, Türkiye

\begin{abstract}
The most obvious effect of global climate change on meteorological conditions is on temperature and precipitation. The negative effects of both flood and drought events are increasing day by day. While all natural disasters reveal the importance of climate change, they also bring the evaluation of meteorological events to a more important point. For this purpose, by examining the precipitation observation data in the Western Black Sea Basin, precipitation variability and possible risk areas related to this variability were defined, and risk maps were obtained as a result of regional analysis. Long term precipitation data of 13 meteorological stations in the Basin were taken into account and the variability in the observed precipitation was defined with the Intensity Variability Index (IVI) based on Intensity Entropy (IE). After the irregularities in precipitation were defined with indices, regions with high probability of precipitation were determined with index-based maps, created based on these indices. The produced entropy-based maps will be an effective tool for the planning of decision makers when faced with climate change and flood risk.
\end{abstract}

Keywords: West Black Sea Basin, Variability, Entropy, Intensity variability index, Precipitation, Türkiye

\footnotetext{
${ }^{{ }^{* a}}$ Filiz BARBAROS; filiz.barbaros@deu.edu.tr, Tel: (0232) 30170 54, orcid.org/0000-0002-2697-911X
} 


\section{Giriş \\ 1. Introduction}

Doğal afetler canlıların yaşamında sonuçları ölümle sonuçlanabilecek derecede olumsuz etkileri olan olaylardır. Afetlerin taşıdığ 1 tehlikelere karş1 önlemler alabilmek için, doğal süreçlerin detaylı bir şekilde izlenmesi ve belirlenmesi gerekir. Araştırmacılar yıllar boyunca bu amaçla meteorolojik olayları çeşitli yöntemlerle değerlendirmişlerdir. Yaşanan tüm doğal afetler son y1llarda etkisi daha belirgin bir şekilde hissedilen iklim değişikliğinin önemini daha çok ortaya koyarken, meteorolojik olayların değerlendirilmesini de daha önemli bir noktaya taşımaktadır. $\mathrm{Su}$ kaynaklarının yönetimi çerçevesinde ele alınan en önemli konulardan biri olan hidrolojik süreçlere ait gözlemlerin yapılması ve bu gözlemlerden elde edilen verilerin en etkin yöntemlerle değerlendirilmesi de meteorolojik süreçler hakkında bilgi edinmek için en etkili yöntemlerdir. Su kaynakları sistemlerinin karmaşık ve stokastik bir yapıya sahip olması nedeniyle, baş edilmesi gereken temel sorunlar olarak belirsizlik ve değişkenlik ortaya çıkmaktadır. Dolayısıyla, karar vericiler için çoğunlukla bilgi eksikliği vardır ve bu durumda araştırmacıların çalışma ve deneyimleri çok önemli olmaktadır.

Hidro-meteorolojik değişkenlerin uzun dönem zaman serilerinin incelenmesi, potansiyel su kaynaklarını değerlendirmek ve çevresel değişiklikleri incelemek için hayati öneme sahiptir (Gu vd., 2020). Uzun dönem hidro-meteorolojik değişkenlerin analizi, su kaynakları planlaması ve iklim değişikliği etkileri çalışmalarında önemli bir rol oynamaktadır (Mishra vd., 2009). Genel olarak küresel isınma, hidrolojik döngüyü yoğunlaştırmakta ve dolayısyla küresel ortalama yağış, buharlaşma ve yüzey akışını artırmaktadır (Clark vd., 1999).

İklim değişikliğinin ve su kaynakları yönetiminin bölgesel etkilerini değerlendirmek için yağışın alansal ve zamansal özelliklerini ölçmek esastır (Zhang vd., 2016). Yağış rejimlerindeki alansal ve zamansal farklılıkları anlamak, hidrolojik döngünün iklim değişikliğine tepkisini ve bunun bölgesel ve küresel ölçekte su kaynaklarının değişkenliği ve kullanılabilirliği üzerindeki etkisini anlamak için önemlidir (Zhang vd., 2011; Cleridou vd., 2014).

Meteorolojik gözlemler rastgele bir sayı dizisi niteliğindedir. Yönetim kapsamında yer alan araştırmacılar, planlamacılar ve karar vericiler, bu veri dizisinden elde edilebilecek en fazla bilgiyi edinmek üzere çeşitli çalışmalar yürütmektedirler.
Gözlem yapılarak toplanan verilerden bilgi edinmek üzere "bilgi kuramı" ile tanımlanan, "kazanilan bilgi = giderilen belirsizlik" anlamın taşıyan entropi kavramı nesnel bir ölçüt olarak kullanılmaktadır. Entropi, rastgele karakterdeki hidrolojik süreçlerin içerdiği belirsizliğin ölçüsü olarak tanımlanmaktadır (Baran vd., 2017).

Hidrolojik sistemler, çok çeşitli alansal ve zamansal değişim ölçekleriyle çok karmaşıktır. Bu değişkenliği anlamak ve tahmin etmek, gelecekteki değişiklikleri tahmin etmek için kritik öneme sahiptir. Entropi ve ilgili yöntemler, hidrolojik sistemin değişkenliğini anlamada yardımcı olur. İzlenen meteorolojik veriler rastgele olduğundan, periyodik olarak ölçülmeyen değişkenin belirsizliği hakkında bilgi akışı ile ilgili uygulama, ilk olarak Shannon ve Weaver (1949) tarafindan tanımlanan entropi teorisi ile mümkün olmuştur. 1989'da Singh, hidrolojik modelleme üzerine entropi teorisini ilk kez uygularken, Harmancioglu vd. (1992b), su kaynakları ve hidrolojik modellemede entropiyi kullanmıştır (Harmancioglu, 1981; Harmancioglu \& Alpaslan, 1992; Harmancioglu vd., 1992a).

Entropi tabanlı değerlendirmeler, genellikle değişkenliği tanımlayan çeşitli istatistikler arasındaki olasılık dağılımı hakkında en fazla bilgiyi içerir ve yağış dağılımının yıllık, mevsimlik veya aylık gibi birçok ölçekte değerlendirilebilmesini mümkün kılar (Gu vd., 2020). Son y1llarda, bilgi teorisine dayali yaklaşımlar, hidrometeorolojik verilerdeki değişkenliğin, hidrometrik izleme ağlarının ve yağı̧̧ rejimlerinin alansal ve zamansal değerlendirilmesi gibi çok uygulamalarda kullanılmıştır (Koutsoyiannis, 2005; Li vd., 2012; Cui \& Singh, 2012; Alfonso vd., 2014; Zhang vd., 2016; Cheng vd., 2017; Bacanlı vd., 2017; Okkan \& Altun, 2019).

Sunulan çalışmada da adı geçen yöntem, Batı Karadeniz havzasinda bulunan 13 meteoroloji gözlem istasyonunda 1975-2012 yılları arasında gözlemi yapılmış yağışlar özelinde uygulanmıştır. Uzun dönem yağış verilerinin alansal ve zamansal değişkenlikleri entropi tabanlı yöntemler ile değerlendirilmiştir.

\section{Entropi kavramı \\ 2. Entropy concept}

Entropi, termodinamik ve istatistiksel mekaniğin çok önemli bir kavramıdır ve incelenen sistemin türü veya boyutu ne olursa olsun, o sistemden 
edinilecek bilgi miktarını en iyi şekilde tanımlar (Wehri, 1978).

Entropi, Shannon (1948) tarafindan tanımlanan, bilgi teorisi kullanılarak, kesikli veya sürekli formda verilen bir rastgele değişkenin, bilinen veya hesaplanan olasılık dağılım fonksiyonu veya olasılık yoğunluk fonksiyonu ile belirlenen bir değerdir. Entropi, düzensizlik, kaos veya belirsizliğin bir ölçüsü olarak kabul edilir (Singh, 2014). Bir değişkenin değişkenliğindeki artış, olasılık dağılımının çarpıklığını azaltacak ve dolayısıyla entropi değerinde bir artışa neden olacaktır. Olasılık dağılımının herhangi bir sapma olmaksızın tekdüze olması durumunda entropi maksimum değerini alırken, herhangi bir olasılığa sahip değişkenin belirli bir değeri alması entropi değerinin sıfira yaklaşmasına yol açar (Singh, 2018). Entropi, süreçlerdeki belirsizliği netleştirmek ve o süreçten alınabilecek en fazla bilgi miktarını belirlemek için uygulanır. Özellikle su kaynakları sistemlerindeki belirsizliğin ölçümü, su arz ve talepleri arasındaki önemli zamansal ve mekânsal uyumsuzlukları belirlemek ve iklim değişikliğinin etkileri ile daha riskli hale gelecek bölgeleri tahmin etmek üzere çeşitli araştırmacılar tarafından yürütülen çalışmalar ile ele alınmıştır (Singh, 1997; Maruyama vd., 2005; Renard vd., 2020; Rehana vd., 2020; Ciriello vd., 2021).

$\mathrm{Su}$ kaynakları yönetimi kapsamında, entropi teorisine dayalı yaklaşımlar, çeşitli araştırmacılar tarafından kullanılmıştır. Entropinin, kavramları ve teknikleri açısından geniş bir uygulama alanına sahiptir. Bu nedenle, belirsizlik içeren birçok konu, çevre ve su mühendisliğinde entropi kullanımıyla çözüm bulmuştur (Singh, 2013; Cui vd., 2018).

Tüm uygulandığı alanlarda entropi, belirli bir problemin çözümü için temel değerlendirme arac1 olarak kullanılmaktadır. 1990'lardan günümüze, su mühendisliği kapsamında yapılan birçok çalışmada, belirsiz bir durumu çözmek için entropi yaygın bir biçimde kullanılmıştır. $\mathrm{Bu}$ nedenle entropi ile belirsizlik değerlendirme yöntemi, çevre ve su kaynaklarında modelleme ve karar verme için etkili araçlardan biridir (Singh, 2000).

\section{Değişkenlik ölçütleri}

\section{Variability criteria}

Mishra vd. (2009) yaptığı çalışma ile değişkenliği, alansal ve zamansal olarak tanımlamıştır. Farklı coğrafi konumlarda gözlenen bir özellik için alansal değişkenliğin, farklı değerlerle ifade edildiğini belirtmiştir. Alansal değişkenliğin, herhangi bir yağış istasyonunun bölgedeki toplam yağışa katkısının dikkate alınması, ya da her bir istasyondaki yağış kayıtlarının içindeki değişkenliğin karşılaştırılması; zamansal değişkenliğin ise farklı zaman aralıklarında gözlenen bir zaman serisinin düzensizliğinin ölçülmesi şeklinde yapılabileceğini ortaya koymuştur.

Bir zaman serisinin değişkenliğini ölçmek için kullanılan tanımlayıcı istatistikler genelde, veri aralığı, ortalama, standart sapma ve değişkenlik katsayısıdır. Değişkenliği tanımlamak için kullanılan en yaygın istatistik gösterge ise bir veri setindeki yayılımı ölçen varyanstır. İstatistikte rastgele bir değişkenin varyansı, olası değerlerinin beklenen değerden (ortalama) olan uzaklığının karesinin ortalaması alınarak tanımlanan istatistiksel dağılımın bir ölçüsüdür (Mishra vd., 2009). Yağış değişkenliğinin analizi için de farklı varyans yöntemleri yaygın olarak kullanılmaktadır. Sunulan çalışmada ise entropi kavramı, yağışın alansal ve zamansal değişkenliğini belirlemek için kullanılmıştır.

\section{Yöntem \\ 4. Method}

Bir sistemin belirsizliğinin ölçüsü olan entropi yöntemi, ilgili konular çerçevesinde birçok alanda kullanılmıştır. Çalışmada kullanılan yöntem, çeşitli araştırmacılar tarafından farklı havzalarda uygulanmış ve uygulanan havzalardaki yağış değişkenliklerinin değerlendirilmesi için etkin bir yöntem olarak örnekler verilmiştir (Huh vd., 2005; Zhang vd., 2016; Cheng vd., 2017; Roushangar vd., 2019; Gu vd., 2020).

Sunulan çalışmada gözlenmiş yağış verileri rastgele değişken olarak kabul edilmiş ve gözlem istasyonlarından alınan uzun dönem yağış verileri entropi yöntemi ile değerlendirmeye alınmıştır.

Bilgi içeriğinin belirlenmesi için kullanılan, marjinal entropi $H$, sürecin gözlenmesi sonucunda giderilen belirsizlik anlamına gelmektedir. Kesikli bir değişken için entropi, Shannon (1948) tarafından denklem 1 ile tanımlanmıştır.

$H=-\sum_{k=1}^{K} p\left(x_{k}\right) \log \left[p\left(x_{k}\right)\right]$

Burada; $k, K$ adet olayın zaman aralı̆̆ $; x_{k}, k$ aralığına karşılık gelen olay ve $p\left(x_{k}\right), x_{k}$ olayının olasılığıdır.

Mishra vd. (2009)'e göre, marjinal entropi, şiddet entropisi ve paylaştırılmış entropi gibi çeşitli 
entropi ölçütleri, değiş̧kenliğin belirlemesi amacıyla kullanılır. Entropi teorisinin yağışların alansal ve zamansal değişkenliklerinin belirlenmesi amacıyla kullanılması, çeşitli çalışmalarda ele alınmıştır (Zhang vd., 2016; Cheng vd., 2017; Gu vd., 2020). Çalışmalarda, günlük, mevsimlik, aylık ve yıllık gibi farklı zaman ölçeklerinde, aşağıda verilen entropi ölçütleri, değişkenlik indisi hesaplamalarında kullanılır.

Marjinal Entropi (ME): Marjinal Entropi (ME), belirsizliği ölçmek için kullanılan, olasılık dağılımı $p(x)$ olan rastgele bir değişken $x$ 'in ortalama bilgisidir. Hesaplama işlemleri Eşitlik 1 ile ifade edilmektedir.

Şiddet Entropisi (ŞE): Şiddet Entropisi (ŞE) hesaplanırken, herhangi bir yılın i. ay1 $(i=1,2,3$, $\ldots, 12)$ içindeki yağışlı günlerin $\left(n_{i}\right)$ sayısı ve yıldaki toplam ölçümü olan yağış günleri, $N(N=$ $\sum n_{i}$ ) dikkate alınmaktadır (Mishra vd., 2009). Her aydaki yağışı günlerin olasılıkları $p_{i}=n_{i} / N$ olarak, o ay için tek bir meteoroloji istasyonunun Şiddet Entropisi (SSE) denklem 2 ile ifade edilmektedir (Mishra vd., 2009).

$\mathrm{S} E=-\sum_{i=1}^{m}\left(\mathrm{n}_{i} / N\right) \log _{2}\left(n_{i} / N\right)$

Paylaştırılmış Entropi (PE): Paylaştırılmış Entropi (PE), bir yıl boyunca farklı aylar için yağışların dağglım özelliklerini incelemek üzere kullanılmaktadır. $i$. aydaki yağış miktarının $r_{i}(i=$ $1,2,3, \ldots, 12)$ ve on iki aylık toplam yağış miktarının $R=\sum_{i=1}^{12} r_{i}$ olduğu varsayımı ile, her aydaki yağış günlerinin bir yıldaki toplam gün sayısına oranı $p_{i}=r_{i} / R$ olarak ifade edilir. Bir y1l için tek bir meteoroloji istasyonu için $P E$, denklem 3 ile hesaplanmaktadır (Mishra vd., 2009).

$P E=-\sum\left(\mathrm{r}_{i} / R\right) \log _{2}\left(r_{i} / R\right)$

PE değeri, 0 ile $\log _{2}(12)$ aralığında olup, yağışın on iki aydan sadece birinde meydana geldiği ve yıllık yağış miktarının sırasıyla on iki ay boyunca eşit olarak dağıldığının öngörüldüğü aralıkta hesaplanmaktadır (Mishra vd., 2009).

Entropiye dayalı Değişkenlik: Entropiye dayalı değişkenlik, Değişkenlik İndisi (DI) ile tanımlanır. $D \dot{I}$, mümkün olan maksimum entropi $(\max H)$ ile tekil bir zaman serisinden hesaplanan entropi arasındaki fark olarak, denklem 4 ile hesaplanır.
$D \dot{\mathrm{I}}=\max H-H$

Değişkenin düzgün dağılıma sahip olması durumunda Eş. (1)'de tanımlanan Shannon entropisi maksimum değerine ulaşır. Bu nedenle, $H^{\prime}$ in değişim aralığı $[0, \log \mathrm{N}]$ arasında değişir. Burada $R$, mevcut veri setinde rastgele değişken tarafından alınan en düşük ile en yüksek değer arasındaki farktır ve denklem 5 ile ifade edilir (Xiong vd., 2018; Bozoğlu vd., 2022).

$\max H=\log (R)$

Entropi değerlerinin maksimum entropi değerinden fark1 ile hesaplanan $D \dot{I}$, analiz edilen zaman serilerinin değişkenlik özelliklerinin bilgisini taşır. $D \dot{I}$ değeri ne kadar yüksekse, değişkenlik de o kadar yüksek olacaktır. Yıllık, mevsimlik, aylık veya günlük zaman serilerinden hesaplanan entropi değerlerine dayalı olarak belirlenen indisler, o zaman serisinin değişkenliğini belirler. Alansal ve zamansal değişkenlik, hesaplanan bu indislere dayalı olarak karşılaştırılabilir.

$D \dot{I}$, marjinal entropiden hesaplandığında, Marjinal Değişkenlik İndisi $(M D \dot{I})$ olarak bilinir. Benzer şekilde, paylaştırılmış entropiye dayalı Paylaştırılmış Değişkenlik İndisi $(P D \dot{I})$ veya şiddet entropisine dayalı Şiddet Değişkenlik İndisi (ŞDI) değerleri hesaplanabilir. Hesaplanan on y1llik paylaştırılmış entropi değerlerinden indisler ise, On yıllık Paylaştırılmış Değişkenlik İndisi (OPDI) adını alır.

\section{5. Çalışma alanı ve uygulama}

\section{Study area and application}

Karadeniz Bölgesinde yer alan Batı Karadeniz Havzas1, $40^{\circ} 34^{\prime} 42^{\prime \prime}-41^{\circ} 27^{\prime} 52^{\prime \prime}$ kuzey enlemleri ve $30^{\circ} 52^{\prime} 33^{\prime \prime}-35^{\circ} 12^{\prime} 12^{\prime \prime}$ doğu boylamları arasında yer almaktadır. Havzanın büyük bir bölümü Düzce, Zonguldak, Bartın, Karabük illeri idari sınırları içerisinde olup, kalan diğer bölümü ise Bolu, Çankırı, Kastamonu ve Sinop illerinin sinırları içerisinde yer alır (TÜBITTAK MAM, 2013). 2,892,239 hektarlık havza alanı ile Türkiye yüzölçümünün yaklaşı \%3.7'sini kapsayan Batı Karadeniz Havzası 28,855 $\mathrm{km}^{2}$ yağış alanına sahiptir. Havza genel durum haritası Şekil 1'de verilmiş̧tir. Havzada ortalama yıllık yağış $774.05 \mathrm{~mm}$, ylllık ortalama akım ise $10.8 \mathrm{~km}^{33}$ tür. (SYGM, 2019). 


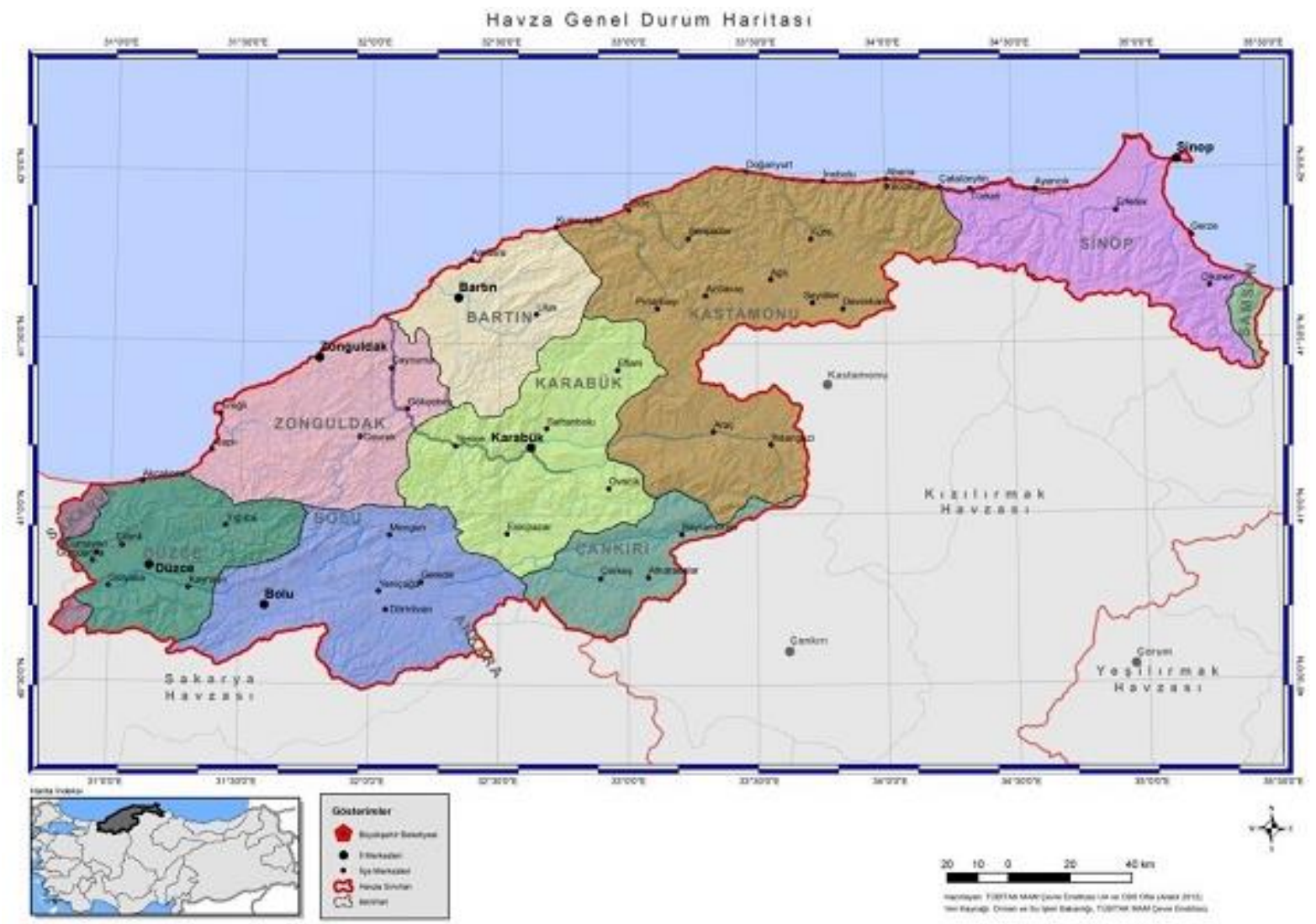

Şekil 1. Bat1 Karadeniz Havzası (TÜBİTAK MAM, 2013)

Figure 1. West Black Sea Basin (TÜBITTAK MAM, 2013)

TÜBİTAK Marmara Araştırma Merkezi Çevre ve Temiz Üretim Enstitüsü tarafından 2013 yılında Batı Karadeniz Havzası için hazırlanan "Havza Koruma Eylem Planlarının Hazırlanmasl Projesi" kapsamında 1975-2010 yılları arasındaki yağış verileri üzerinden, ortalama ve maksimum yağışlar konumları ile birlikte değerlendirilmiş ve taşkın açısından önemli bölgeler belirlenmiştir (TÜBİTAK MAM, 2013). Maksimum yağış değerlerine göre en yüksek yağış $431.5 \mathrm{~mm}$ olarak Ağustos ayında Zonguldak istasyonunda, en düşük maksimum yağış değeri ise $62.8 \mathrm{~mm}$ ile Şubat ayında Çankırı istasyonunda kaydedilmiştir. Yapılan benzer çalışmalara göre, yıllık alansal ortalama yağış miktarı ve yıllık toplam yağışlar açısından, Batı Karadeniz Havzasına ait değerler Türkiye ortalamasının üzerindedir (Kayhan ve Alan, 2012; Büyükkaracığan, 2019). İklimi açısından havza değerlendirildiğinde, sahil şeridinden içeriye doğru gidildikçe İç Anadolu iklim şartları görülmektedir. Havzanın kuzeyinde Karadeniz iklimi görülürken, güneye doğru Karadeniz iklimi ile İç Anadolu iklimi arasında geçiş iklimi görülmektedir (SYGM, 2019). T. C. Orman ve Su İşleri Bakanlığı, Su Yönetimi Genel Müdürlüğü tarafindan 2016 yılında tamamlanan "İklim Değişikliğinin Su Kaynaklarına Etkisi Projesi” ile sıcaklık ve yağış verileri üzerinden projeksiyonlar yapılarak gelecek senaryoları hakkında öngörüler paylaşılmıştır (SYGM, 2016).

Çeribaş1 (2018) tarafindan Bat1 Karadeniz Havzası'nda yapılan bir çalışmada, iklim değişikliğinin etkisiyle yağışlarda olabilecek değişimler incelenmiş, istasyonlar bazında farklı eğilimler tespit edilmiştir. Anılan çalışma bulguları ile sunulan çalışma kapsamında yă̆ış değişkenlikleri için önerilen yöntemin birlikte uygulanması ve değerlendirilmesi, havzada su kaynakları yönetim planlaması için verilecek bütüncül bir karar için alt yapıyı oluşturacaktır (Çeribaş1, 2018).

Çalışma kapsamında, havzada yer alan 13 adet meteoroloji gözlem istasyonuna ait 1975-2012 yıllarına ait yağış verileri incelenmiştir. İstasyonlara ait genel bilgiler Tablo 1'de verilmiştir. 
Tablo 1. İstasyonlara ait genel bilgiler (SYGM, 2019)

Table 1. General information of the stations (SYGM, 2019)

\begin{tabular}{|c|c|c|c|c|}
\hline İstasyon No & İstasyon Adı & Enlem & Boylam & Yükseklik (m) \\
\hline 17070 & Bolu & $40^{0} 44^{\prime} 39^{\prime \prime}$ & $31^{0} 36^{\prime} 08^{\prime \prime}$ & 740 \\
\hline 17646 & Çerkeş & $40^{\circ} 48^{\prime} 53^{\prime \prime}$ & $32^{0} 52^{\prime} 59^{\prime \prime}$ & 1126 \\
\hline 17072 & Düzce & $40^{0} 50^{\prime} 37^{\prime \prime}$ & $31^{0} 08^{\prime} 57^{\prime}$, & 146 \\
\hline 17612 & Akçakoca & $41^{0} 05^{\prime} 21^{\prime \prime}$ & $31^{0} 03^{\prime} 34^{\prime \prime}$ & 10 \\
\hline 17078 & Karabük & $41^{0} 11^{\prime} 38^{\prime}$, & $32^{0} 37^{\prime} 25^{\prime \prime}$ & 259 \\
\hline 17022 & Zonguldak & $41^{0} 26^{\prime} 57^{\prime \prime}$ & $31^{0} 48^{\prime} 00^{\prime \prime}$ & 135 \\
\hline 17618 & Devrekani & $41^{0} 35^{\prime} 58^{\prime \prime}$ & $33^{0} 50^{\prime} 04^{\prime \prime}$ & 1050 \\
\hline 17020 & Bartın & $41^{0} 37^{\prime} 29^{\prime \prime}$ & $32^{\circ} 21^{\prime} 25^{\prime \prime}$ & 33 \\
\hline 17602 & Amasra & $41^{0} 45^{\prime} 09^{\prime \prime}$ & $32^{\circ} 22^{\prime} 58^{\prime \prime}$ & 73 \\
\hline 17604 & Cide & $41^{0} 52^{\prime} 57^{\prime \prime}$, & $32^{0} 56^{\prime} 51^{\prime \prime}$ & 36 \\
\hline 17606 & Bozkurt & $41^{0} 57^{\prime} 37^{\prime \prime}$ & $34^{0} 00^{\prime} 13^{\prime \prime}$ & 167 \\
\hline 17024 & İnebolu & $41^{0} 58^{\prime} 44^{\prime \prime}$ & $33^{0} 45^{\prime} 49^{\prime}$ & 64 \\
\hline 17026 & Sinop & $42^{0} 01^{\prime} 47^{\prime \prime}$ & $35^{0} 09^{\prime} 16^{\prime \prime}$ & 32 \\
\hline
\end{tabular}

Mevcut uzun dönem yağış verilerinin zamansal ve alansal değerlendirilmesinde Şiddet Entropisi yöntemi uygulanmış; Şiddet Entropisi (ŞE) değerleri denklem 2; Şiddet Değişkenlik Indisleri
(ŞDI) ise denklem 4 kullanılarak hesaplanmıştır. İstasyonlara ait uzun dönem günlük yağış verileri üzerinden hesaplanan şiddet entropileri ve indis değerleri Tablo 2'de verilmektedir.

Tablo 2. Uzun dönem yağış verilerinden hesaplanan Şiddet Entropisi (ŞE) ve Şiddet Değişkenlik İndisleri (ŞDİ) Table 2. Intensity Entropy (IE) and Intensity Variability Indices (IVI) calculated from long-term precipitation data

\begin{tabular}{cccc}
\hline İstasyon No & Şiddet Entropisi (ŞE) & İstasyona ait Maksimum Entropi & Şiddet Değişkenlik İndisi (ŞDí) \\
\hline 17070 & 0.2887 & 1.7597 & 1.4710 \\
17646 & 0.1906 & 1.7259 & 1.5353 \\
17072 & 0.4680 & 2.0426 & 1.5746 \\
17612 & 0.6169 & 2.3367 & 1.7198 \\
17078 & 0.2796 & 1.8976 & 1.6180 \\
17022 & 0.6876 & 2.1700 & 1.4824 \\
17618 & 0.2566 & 1.7451 & 1.4885 \\
17020 & 0.5842 & 2.0358 & 1.4516 \\
17602 & 0.5654 & 1.9552 & 1.3898 \\
17604 & 0.6684 & 2.1461 & 1.4777 \\
17606 & 0.6936 & 2.1014 & 1.4078 \\
17024 & 0.5846 & 2.1173 & 1.5327 \\
17026 & 0.3842 & 2.1245 & 1.7403 \\
\hline
\end{tabular}

Sunulan çalışmada hesaplamalar, mevcut uzun dönem günlük yağış verileri üzerinden yapıldığı gibi, mevsimsel olarak da detaylandırılmıştır. Değerlendirmelerde, Mart, Nisan, Mayıs aylan ilkbahar; Haziran, Temmuz, Ağustos ayları yaz; Eylül, Ekim, Kasım ayları sonbahar ve Aralık, Ocak, Şubat ayları ise kış mevsimi olarak dikkate alınmıştır.

Farklı meteoroloji istasyonlarındaki uzun dönem ve mevsimlik (ilkbahar, yaz, sonbahar ve kış) yağış zaman serilerinden hesaplanan Şiddet Düzensizlik Indisleri (ŞDI) Şekil 2'de verilmiştir. Genel olarak, ŞDİ değerlerinin kış mevsiminde diğer mevsimlere göre daha düşük olduğu gözlenmiştir. Kış mevsiminde incelenen yağışların düşük değişkenliğe sahip olduğu görülmüştür. Yaz mevsimi için ise daha yüksek ŞDİ değerleri hesaplanmış; bu durum da yaz aylarında analiz edilen istasyonlardaki yağı̧ değerlerinin yüksek değişkenliklerine işaret etmiştir.
Hesaplanan ŞDİ değerlerinin uzun dönem ölçeğindeki alansal dağılımı, 1975-2012 dönemi için ortalama günlük yağışla karşılaştırmalı olarak Şekil 3'te verilmiştir. Batı Karadeniz Havzasında yıllık yağışın güneyden kuzeye doğru yaklaşık 1-4 $\mathrm{mm} /$ gün aralığında değiştiği görülmektedir. Alansal olarak değerlendirildiğinde, en yoğun değiş̧kenlik görülen alanların, yüksek yağış alan kıyı bölgelerinde olduğu belirlenmiştir. TÜBİTAK MAM tarafindan 2013 y1lında Bat1 Karadeniz Havzası için hazırlanan "Havza Koruma Eylem Planlarının Hazırlanması Projesi" çerçevesinde yapılmış çalışma bulgularına paralel olarak, sunulan çalışmada yapılan değerlendirmeler sonucunda da, hesaplanan ŞDİ değerleri açısından yükssek değiş̧kenliğe sahip olan bölgelerin, yă̆ış ortalamasının en fazla olduğu Şekil 3a'da görülen 17020 - Bartın ve 17022 - Zonguldak istasyon bölgeleri olduğu görülmüştür. Dolayısıyla, Batı Karadeniz havzası için Şekil 3b'ye göre, yüksek ŞDİ değerli yüksek değişkenliğe sahip bölgeler, 
yağış açısından yüksek değişkenlik özellikleri ile uç değerlerin görülme olasıllı̆ı yüksek bölgeler olarak değerlendirilebilir.

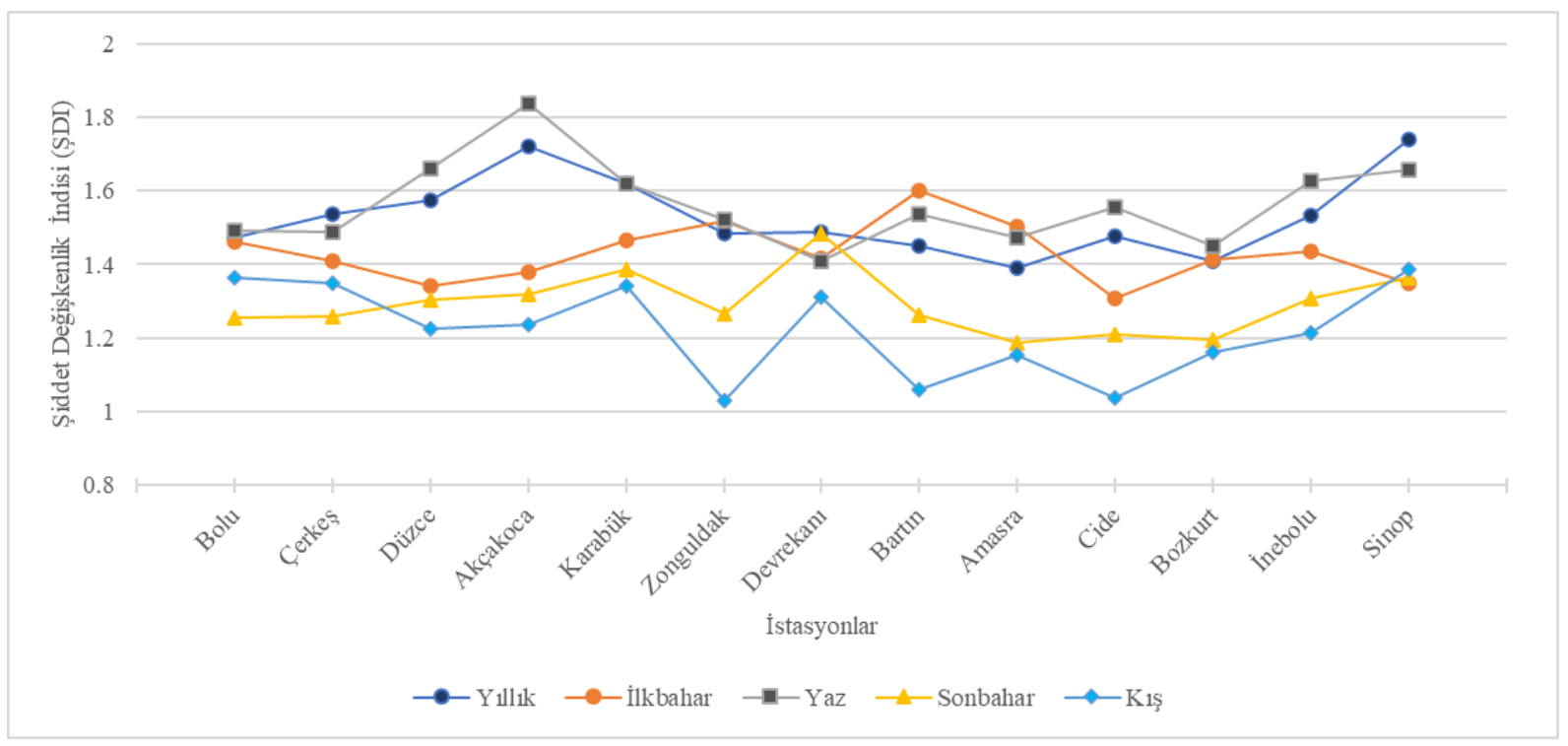

Şekil 2. Batı Karadeniz Havzasında yıllık ve farklı mevsimlere ait zaman serileri arasında Şiddet Değişkenlik İndislerinin (ŞDI) karşılaştırılması

Figure 2. Comparison of Intensity Variability Indices (IVI) between annual and seasonal time series in the Western Black Sea Basin
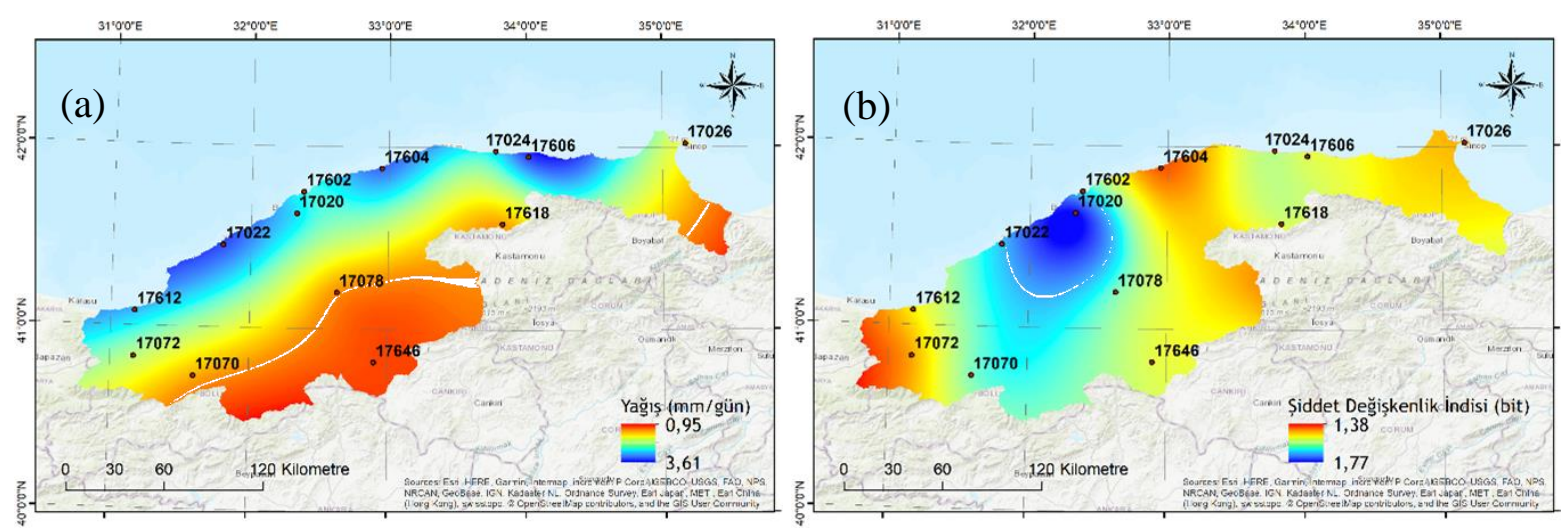

Şekil 3. Batı Karadeniz Havzasında, (a) ortalama günlük yağış ve (b) Şiddet Entropisine (ŞE) dayalı uzun dönem günlük zaman serilerinden hesaplanan Şiddet Değişkenliği Indisi (ŞDI) değerlerinin alansal dağılımları

Figure 3. Spatial distributions of (a) average daily precipitation and (b) Intensity Variability Index (IVI) values calculated from long-term daily time series based on Intensity Entropy (IE) in the Western Black Sea Basin

Mishra vd. (2009) yaptığı çalışmada, mevsimsel değişkenlikten hangi ayın sorumlu olduğunu anlamak için o mevsim içindeki ayların değişkenliğinin de incelenmesinin yararlı olacağını ifade etmiştir. Bu amaçla hazırlanan Şekil 4-7 incelendiğinde, her bir ayın entropi tabanlı değişkenliğinin, ait olduğu mevsimin değeri ile birebir aynı olmadığı görülmektedir. Bu durum, temel olarak yağışın düzensiz doğası ile açıklanabilir. 


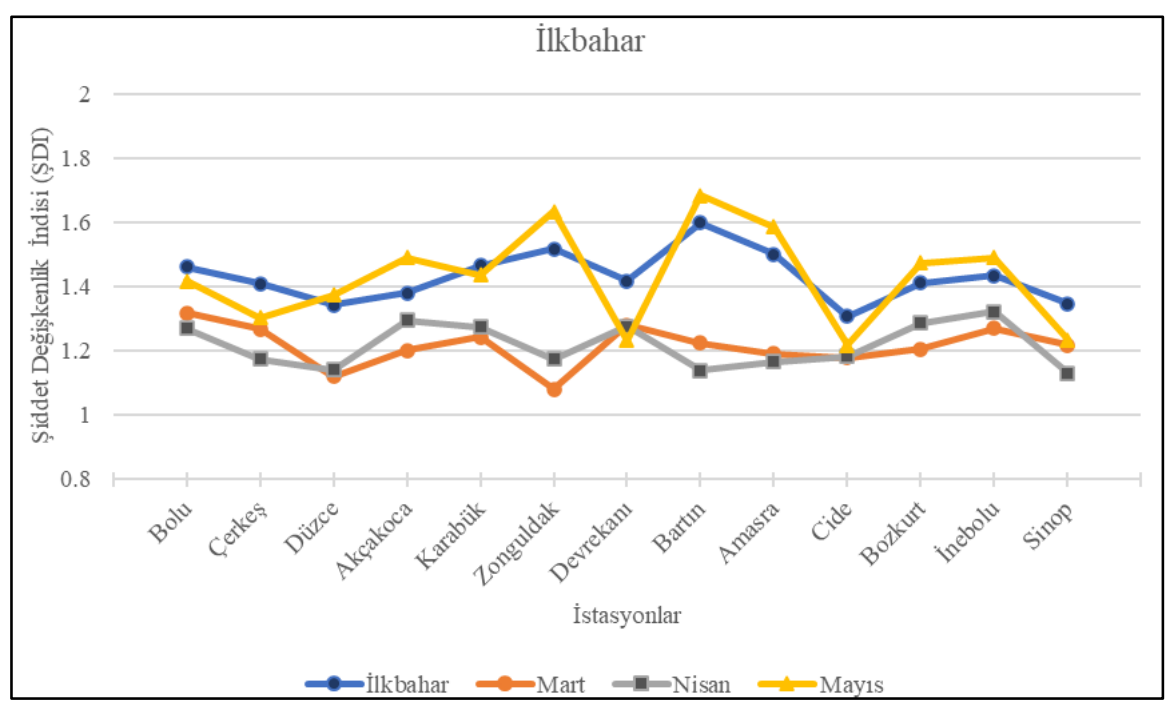

Şekil 4. Batı Karadeniz Havzasında farklı istasyonlardaki yağış zaman serilerinin ilkbahar mevsimine ait Şiddet Değişkenlik Indisleri (ŞDI)

Figure 4. Intensity Variability Indices (IVI) of precipitation time series at different stations in the Western Black Sea Basin for the spring season

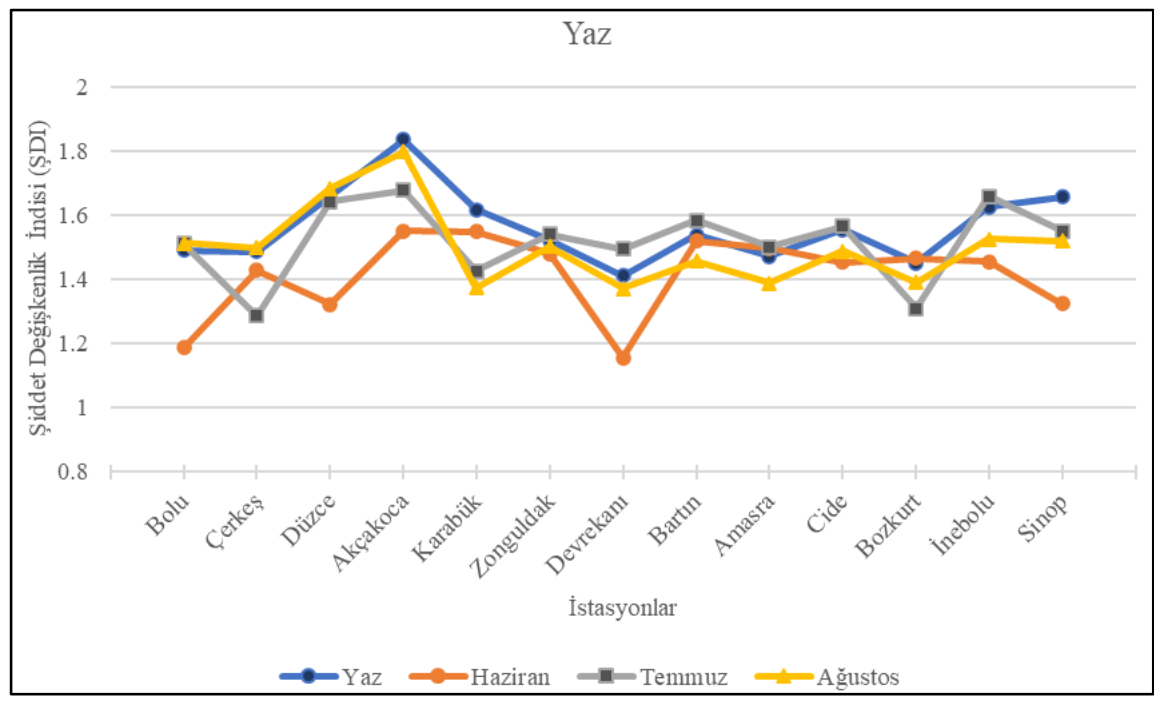

Şekil 5. Batı Karadeniz Havzasında farklı istasyonlardaki yağış zaman serilerinin yaz mevsimine ait Şiddet Değişkenlik İndisleri (ŞDI)

Figure 5. Intensity Variability Indices (IVI) of precipitation time series at different stations in the Western Black Sea Basin for the summer season

Mevsimlere göre ŞDI grafiklerinin istasyonlar bazında gidişleri değerlendirildiğinde, aylara ait en benzer gidişler kış mevsiminde görülmüştür. Mevsim genel değerlendirmesinde etkin olan aylar ilkbahar, yaz, sonbahar ve kış mevsimleri için, sırasiyla Mayıs, Ağustos, Eylül ve Ocak olarak görülmektedir. Mevsim geneli ile aynı gidişe sahip olduğu görülen bu aylar, aynı zamanda mevsim içindeki en yüksek ŞDİ değerlerine sahip olan aylar olarak karşımıza çıkmıştır. Dolayısıyla, Mayıs, Ağustos, Eylül ve Ocak ayları yağış açısından en yüksek değişkenliğe sahip olan aylar olarak değerlendirilebilmektir.
Uzun dönem mevsimsel yağış verilerine ait $S D I$ değerlerinin alansal dağılımı Şekil 8'de gösterilmekte ve her mevsime göre yağış değişkenliğinin etkin olduğu bölgelerin farklı olduğu; Şekil 3b'de verilen yıllık alansal dağılım ile en benzer dağılımın ilkbahar mevsimine ait olduğu gözlenmiştir. Şekil 4-7'de grafik olarak verilen ŞDI değerlerinin Şekil 8'de verilen alansal dağılımı ile o mevsim içindeki yağış açısından en yüksek değişkenliğe sahip bölgeler daha net olarak görülebilmektedir. 


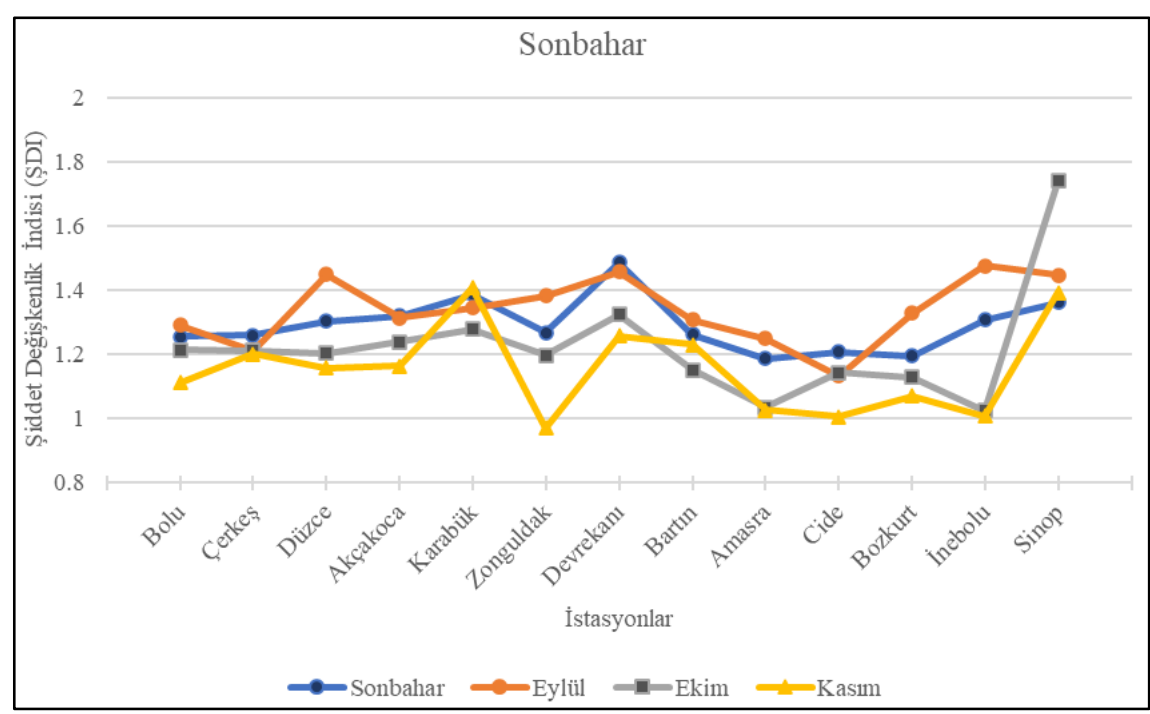

Şekil 6. Batı Karadeniz Havzasında farklı istasyonlardaki yağış zaman serilerinin sonbahar mevsimine ait Şiddet Değişkenlik Indisleri (SSDI)

Figure 6. Intensity Variability Indices (IVI) of precipitation time series at different stations in the Western Black Sea Basin for the fall season

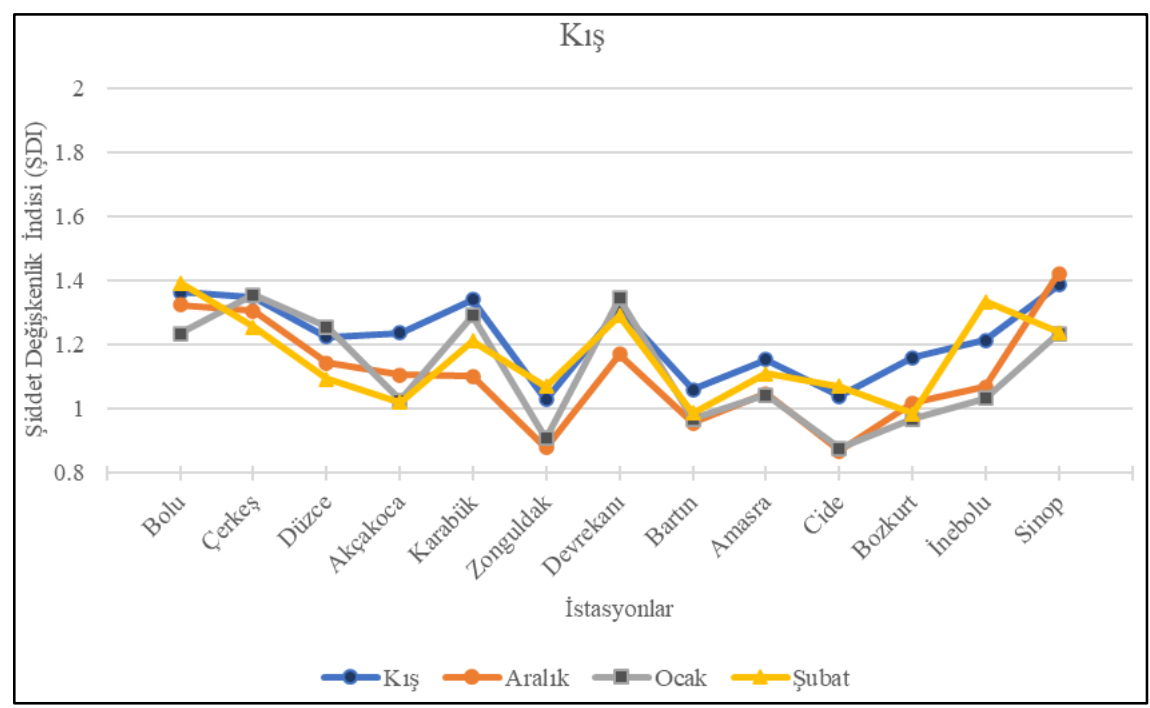

Şekil 7. Batı Karadeniz Havzasında farklı istasyonlardaki yağış zaman serilerinin $k \iota s ̧$ mevsimine ait Şiddet Değişkenlik İndisleri (ŞDI)

Figure 7. Intensity Variability Indices (IVI) of precipitation time series at different stations in the Western Black Sea Basin for the winter season

Yüksek ŞDI değerlerine, dolayısıyla yüksek değişkenliklere karşılık gelen bölgeler Şekil 8'de mavi renk ile gösterilen alanlardır. Mevsimlere göre yüksek değişkenlik gösteren bölgelerin farkl1, ancak sonbahar hariç, kıyı bölgeler olduğu görülmektedir. İlkbaharda 17020 - Bartın ve 17022 - Zonguldak; yaz mevsiminde 17612 - Akçakoca ve 17072 - Düzce; sonbaharda 17618 -Devrekani; kış mevsiminde ise 17026 - Sinop istasyonlarının bulunduğu bölgelerin yağış açısından yüksek değişkenliğe sahip olduğu görülmüştür. $\mathrm{Bu}$ bölgeler değerlendirildiğinde, yıl genelinde en fazla değişkenliğin 17612 - Akçakoca ve 17072 Düzce'de olduğu belirlenmiştir. Elde edilen bu sonuç yine TÜBITAK MAM raporu ile paralellik göstermekte ve havza genelinde maksimum yağı̧̧ ortalamalarının 17612 - Akçakoca istasyonunda ve Ağustos ayında görüldüğü net bir şekilde ifade edilebilmektedir. 

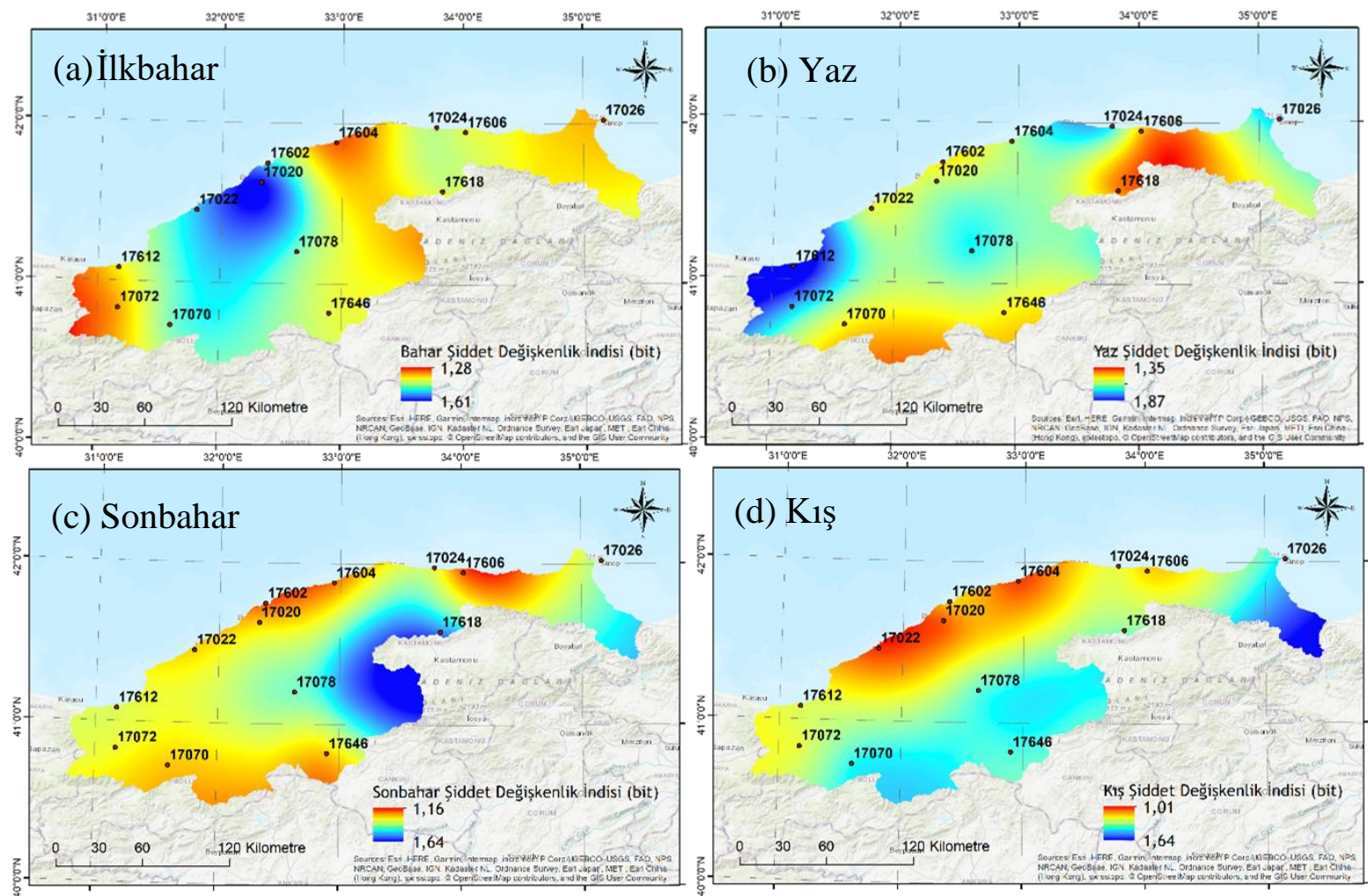

Şekil 8. Batı Karadeniz Havzasında yağış zaman serilerinin Şiddet Değişkenlik İndislerinin (ŞDI) alansal dağılımı; (a) ilkbahar; (b) yaz; (c) sonbahar ve (d) kış

Figure 8. Spatial distribution of Intensity Variability Indices (IVI) of precipitation time series in the Western Black Sea Basin; (a) spring; (b) summer; (c) fall ve (d) winter

\section{Sonuçlar}

\section{Conclusions}

$\mathrm{Su}$ kaynaklarının etkin yönetiminde ve iklim değişikliğinin etkileri ile mücadelede, özellikle meteorolojik olayların etkili bir şekilde değerlendirilmesi ve olaylardan yeterli bilgi edinilmesi gelecek planlamalarında büyük önem taşımaktadır. $\mathrm{Bu}$ noktadan hareketle, yağış verilerinin alansal ve zamansal özelliklerini belirlemek amacıyla yağışın ölçülmesi esastır. Yağış rejimlerindeki alansal ve zamansal değişkenlikleri belirlemek ve etkilerini ortaya koymak, yaşanabilecek afetlere hazırlıklı olmak adına da büyük önem taşır.

Sunulan çalıșma çerçevesinde, yağıșın alansal ve zamansal değişkenliğini belirlemek için entropi yöntemi kullanılmıştır. Batı Karadeniz havzasında bulunan 13 meteoroloji gözlem istasyonunda, 1975-2012 yılları arasında gözlemi yapılmış yağışlar, entropi yöntemi ile değerlendirilmiş ve uzun dönem yağı̧̧ verilerinin alansal ve zamansal değişkenlikleri belirlenmiş̧ir. Mevcut uzun dönem yağı̧̧ verilerinin değişkenlikleri zamansal ve alansal olarak Şiddet Entropisi (ŞE)'ne bağlı olarak Şiddet Değişkenlik İndisleri (ŞDI) ile hesaplanmıştır.
Hesaplanan indisler ile yağışlardaki değişkenlikler hakkında bilgi edinilmesi, istasyon ölçümlerindeki noktasal bilginin değerlendirilmesi, bilgi kaybı olmadan mevcut tüm gözlem verisinin değerlendirmesi mümkündür. Çalışmada kullanılan yöntem ile, hesaplanan entropi değerleri kullanılarak, istasyon bazında noktasal çaptan, havza genelinde risk haritalarının oluşturulması için bölgesel çapta bir analize geçilmiştir. Yapılan değerlendirmeler sonucunda, Batı Karadeniz bölgesi için indislere bağlı oluşturulan indis temelli haritalar yoluyla hem gözlem süresinin tümünde hem de mevsimsel olarak bölünmüş dönemlerde bölgesel riskler görselleştirilmiştir.

Elde edilen risk haritaları, yağışa bağlı risklerin Batı Karadeniz Havzasında 17612 - Akçakoca ve 17072 - Düzce istasyonlarının olduğu alanlarda ve havza genelinde maksimum yağış ortalamalarının 17612 - Akçakoca istasyonunda ve Ağustos ayında görüldügü belirlenmiştir. Bu bilgiler yardımıyla, belirlenen bölgelere özel yüksek yağış değişkenliğine sahip alanlar belirlenebilmekte ve afet riski taşıyan bölgelerde zamanında önlem alınmasını mümkün kılmaktadır. Bölgedeki yağış değişkenliği profili, bir bütün olarak nehir havzaları için mevcut ve gelecekteki yönetim kararlarının alınmasında ve değerlendirme aşamalarında etkin 
rol oynayacaktır. Elde edilen entropi tabanlı haritalar, iklim değişikliği ve taşkın riski ile mücadelede araştırmacılar ve karar vericilerin oluşturacakları planlamalar çerçevesinde etkili bir araç olacaktır.

\section{Teșekkür}

Acknowledgement

Makalenin inceleme ve değerlendirme aşamasında yapmış oldukları katkılardan dolayı ilgili editör ve hakemlere teşekkür ederim.

\section{Etik beyanı}

Declaration of ethical code

$\mathrm{Bu}$ çalışmada, "Yükseköğretim Kurumları Bilimsel Araştırma ve Yayın Etiği Yönergesi" kapsamında uyulması gerekli tüm kurallara uyulduğunu, bahsi geçen yönergenin "Bilimsel Araştırma ve Yayın Etiğine Aykırı Eylemler" başlığı altında belirtilen eylemlerden hiçbirinin gerçekleştirilmediğini taahhüt ederim.

Ayrıca makalenin yazarı, bu çalışmada kullanılan materyal ve yöntemlerin etik kurul izni ve/veya yasal-özel izin gerektirmediğini beyan etmektedir.

\section{Çıkar çatışması beyanı}

Conflicts of interest

Yazar herhangi bir çıkar çatışması olmadığını beyan eder.

\section{Kaynaklar}

\section{References}

Alfonso, L., Ridolfi, E., Gaytan-Aguilar, S., Napolitano, F., \& Russo, F. (2014). Ensemble entropy for monitoring network design. Entropy, 16(3), 1365-1375. https://doi.org/10.3390/e16031365

Bacanl, U. G., Baran, T., \& Dikbaş, F. (2017). Paylaştırılmış entropi kavramının kuraklık ölçütü olarak kullanılabilirliği. Pamukkale Üniviversitesi. Mühendislik Bilimleri Dergisi, 23(3), 232-237. https://doi.org/10.5505/pajes.2016.80664

Baran, T., Harmancioglu, N. B., Cetinkaya, C. P., \& Barbaros, F. (2017). An Extension to the Revised Approach in the Assessment of Informational Entropy. Entropy, 19(12), 634. https://doi.org/10.3390/e19120634

Bozoglu, O., Baran, T., \& Barbaros, F. (2022). Entropy Based Regional Precipitation Prediction in the Case of Gediz River Basin. Teknik Dergi. https://doi.org/10.18400/tekderg.724164
Büyükkaracığan, N. (2019). Hidrolojik Verilerin Değişkenlik Analizi ve Uygulamaları, İKSAD yayınevi, ISBN: 978-625-7029-03-2, $118 \mathrm{~s}$.

Çeribaşı, G. (2018). Batı Karadeniz Havzasının Yağış Verilerinin Yenilikçi Şen Yöntemi ile Analizi, Academic Platform - Journal of Engineering and Science, 6(3), 168-173. https://doi.org/10.21541/apjes.431965

Cheng, L., Niu, J., \& Liao, D. (2017). Entropy-Based Investigation on the Precipitation Variability over the Hexi Corridor in China. Entropy, 19(12), 660. https://doi.org/10.3390/e19120660

Ciriello, V., Lee, J., \& Tartakovsky, D. M. (2021). Advances in uncertainty quantification for water resources applications. Stochastic Environmental Research and Risk Assessment, 35, 955-957. https://doi.org/10.1007/s00477-021-01998-y

Clark, P. U., Alley, R. B., \& Pollard, D. (1999). Northern hemisphere ice-sheet influences on global climate change. Science, 286(5442), 1104-1111.

https://doi.org/10.1126/science.286.5442.1104

Cleridou, N., Benas, N., Matsoukas, C., Croke, B., \& Vardavas, I. (2014). Water resources of Cyprus under changing climatic conditions: modelling approach, validation and limitations. Environ. Model. Softw. 60, 202-218. https://doi.org/10.1016/j.envsoft.2014.06.008

Cui, H., \& Singh, V. P. (2012). On the cumulative distribution function for entropy-based hydrologic modeling. Transactions of the ASABE. 55(2), 429-438. https://doi.org/10.13031/2013.41384

Cui, H., Sivakumar, B., \& Singh, V. P. (2018). Entropy Applications in Environmental and Water Engineering, Entropy, 20, 598, https://doi.org/10.3390/e20080598

Gu, H., Yu, Z., Li, G., Luo, J., Ju, Q., Huang, Y., \& Fu, X. (2020). Entropy-Based Research on Precipitation Variability in the Source Region of China's Yellow River. Water, 12, 2486. https://doi.org/10.3390/w12092486

Harmancioglu, N. B. (1981). Measuring the information content of hydrological processes by the entropy concept. Journal of Civil Engineering, 13-38, Faculty of Engineering, Special Issue for the Centennial of Ataturk's Birth, Ege University, Izmir, Turkey.

Harmancioglu, N. B., \& Alpaslan, N. (1992). Water quality monitoring network design: A problem of multiobjective decision making. Water Resources Bulletin, 28(1), 179-192. 
Harmancioglu, N. B., Alpaslan, N., \& Singh, V. P. (1992a). Application of the entropy concept in design of water quality monitoring networks. Singh, V. P. and Fiorentino, M. (Ed.), Entropy and Energy Dissipation in Water Resources. (s. 283-302.). Kluwer Academic Publishers, Dordrecht.

Harmancioglu, N. B., Singh, V. P., \& Alpaslan, N. (1992b). Versatile uses of the entropy concept in water resources. Singh, V. P. and Fiorentino. M. (Ed.), Entropy and Energy Dissipation inWater Resources. (s. 91-117.). Kluwer Academic Publishers, Dordrecht.

Huh, S., Dickey, D. A., Meador, M. R., \& Ruhl, K. E. (2005). Temporal analysis of the frequency and duration of low and high streamflow: years of record needed to characterize streamflow variability. Journal of Hydrology, 310(1-4), 7894.

Kayhan, M., \& Alan, İ. (2012). Türkiye Alansal Yağış Analizi 1971-2010, Coğrafi Bilgi Sistemleri ile Havza Bazında Alansal Yağış Analizi. Meteoroloji Genel Müdürlüğü. Erişim adresi https://www.mgm.gov.tr/FILES/genel/kitaplar/a lansalyagisanalizi.pdf

Koutsoyiannis D. (2005). Uncertainty, entropy, scaling and hydrological stochastics. 1. Marginal distributional properties of hydrological processes and state scaling. Hydrological Sciences Journal,50(3), 381-404. https://doi.org/10.1623/hysj.50.3.381.65031

Li, C., Singh, V. P., \& Mishra, A. K. (2012). Entropy theory-based criterion for hydrometric network evaluation and design: maximum information minimum redundancy. Water Resources Research, 48, W05521. https://doi.org/10.1029/2011WR011251

Maruyama, T., Kawachi, T., \& Singh, V. P. (2005). Entropy-based assessment and clustering of potential water resources availability. Journal of Hydrology, 309(1-4), 104-113, https://doi.org/10.1016/j.jhydrol.2004.11.020

Mishra, A. K., Özger, M., \& Singh, V. P. (2009). An entropy-based investigation into the variability of precipitation. Journal of Hydrology, 370(1-4), 139-154, ISSN 0022-1694. https://doi.org/10.1016/j.jhydrol.2009.03.006

Okkan, U., \& Altun, H. (2019). Susurluk Havzası Akımlarının Hidrolojik Kuraklık Analizinde Standardize Akım İndeksi ve Paylaştırılmış Entropi Yöntemlerinin Kyyaslanmas1. $4^{\text {th }}$ International Symposium on Innovative Approaches in Engineering and Natural Sciences, SETSCI Conference Proceedings, 4 (6), 329-335. https://doi.org/10.36287/setsci.4.6.084
Rehana, S., Rajulapati, C. R., Ghosh, S., Karmakar, S., \& Mujumdar, P. (2020). Uncertainty Quantification in Water Resource Systems Modeling: Case Studies from India. Water, 12, 1793; https://doi.org/10.3390/w12061793

Renard, P., Delay, F., Tartakovsky, D. M., \& Vesselinov, V. V. (2020). Parameter Estimation and Uncertainty Quantification in Water Resources Modeling. Lausanne: Frontiers Media SA. https://doi.org/10.3389/978-2-88963-674-7

Roushangar, K., Alizadeh, F., Adamowski, J., \& Saghebian, S. M. (2019). Exploring the multiscale changeability of precipitation using the entropy concept and self-organizing maps. Journal of Water and Climate Change, 11(3), 655-676. https://doi.org/10.2166/wcc.2019.097

Shannon C.E. (1948). Mathematical Theory of Information. The Mathematical Theory of Information, 27, 170-180, the University of Illinois Press: Urbana, IL, USA.

Shannon, C. E., \& Weaver, W. (1949). The mathematical theory of communication. Urbana, Illinois: University of Illinois Press.

Singh, V. P. (1989). Hydrologic modelling using entropy. Journal of the Institution of Civil Engineers, 70, 55-60.

Singh, V. P. (1997). The use of entropy in hydrology and water resources. Hydrol. Process. https://doi.org/10.1002/(SICI)10991085(199705)11:6<587:AIDHYP479>3.0.CO;2-P

Singh, V. P. (2000). The Entropy theory as tool for modeling and decision making in environmental and water resources. Water SA, 26,1, ISSN: 0378-4738

Singh, V. P. (2013). Entropy theory and its application in environmental and water engineering. Wiley - Blackwell, USA. https://doi.org/10.1002/9781118428306

Singh, V. P. (2014). Entropy theory in hydrologic science and engineering, McGraw-Hill Education, ISBN: 9780071835466

Singh V. P. (2018). Systems of frequency distributions for water and environmental engineering. Physica A: Statistical Mechanics and its Applications, 506, 50-74, ISSN 0378-4371. https://doi.org/10.1016/j.physa.2018.03.038, 2018.

SYGM (2016) İklim Değişikliğinin Su Kaynaklarına Etkisi Projesi. Tarım Orman Bakanlığı, Su Yönetimi Genel Müdürlüğü. Erişim adresi https://www.tarimorman.gov.tr/SYGM/Belgeler /iklim\%20de\%C4\%9Fi\%C5\%9Fikli\%C4\%9Fin 
in\%20su\%20kaynaklar\%C4\%B1na\%20etkisi/lk lim_Nihai_Rapor_Bat\%C4\%B1_Karadeniz_Ek _15_REV_nihai.pdf

SYGM (2019). Batı Karadeniz Havzası Taşkın Yönetim Planı. Tarım Orman Bakanlığı, Su Yönetimi Genel Müdürlüğü. Erişim adresi http://taskinyonetimi.tarimorman.gov.tr/_engine //_engine/file.axd?file=/Dokumanlar/Havzalar/b ati_karadeniz/bati_karadeniz_typ.pdf

TÜBİTAK MAM (2013) Havza Koruma Eylem Planlarının Hazırlanmast Projesi Batı Karadeniz Havzasl. TÜBİTAK Marmara Araştırma Merkezi. Çevre ve Temiz Üretim Enstitüsü, Proje Kodu: 5118601, Proje Nihai Raporu. Erişim adresi https://www.tarimorman.gov.tr/SYGM/Belgeler /havza\%20koruma\%20eylem\%20planlar\%C4\% B1/Bat\%C4\%B1\%20Karadeniz_web_rev3.pdf

Wehri, A. (1978). General properties of entropy, Reviews of Modern Physics, 50(2), 221-260. https://doi.org/10.1103/RevModPhys.50.221
Xiong, F., Guo, S., Chen, L., Chang, F., Zhong, Y., \& Liu, P. (2018). Identification of flood seasonality using an entropy-based method. Stochastic Environmental Research and Risk Assessment, 32(1-4). https://doi.org/10.1007/s00477-0181614-1

Zhang, Q., Singh, V. P., Sun, P., Chen, X., Zhang, Z., \& Li, J. (2011). Precipitation and streamflow changes in China: changing patterns, causes and implications. Journal of Hydrology, 410(3-4), 204-216.

https://doi.org/10.1016/j.jhydrol.2011.09.017

Zhang, Q., Zheng, Y., Singh, V. P., Xiao, M., \& Liu, L. (2016). Entropy-based spatiotemporal patterns of precipitation regimes in the Huai River basin, China, International Journal of Climatology, 36, 2335-2344. https://doi.org/10.1002/joc.4498 